\title{
Hypersensitivity Eosinophilic Myocarditis in a Patient Receiving Multiple Drug Therapy: Challenges in Diagnosis and Defining the Aetiology
}

\author{
Dario Gulin $^{1,2} \cdot$ Jozica Sikic $^{1,2} \cdot$ Jasna Cerkez Habek $^{1}$ • \\ Sandra Jerkovic Gulin ${ }^{2,3} \cdot$ Edvard Galic $^{1,4}$
}

Published online: 24 September 2016

(C) The Author(s) 2016. This article is published with open access at Springerlink.com

\begin{abstract}
Eosinophilic myocarditis (EM) is a rare and potentially fatal disease if left untreated. Because the disease can have a delayed presentation and can appear even after 2 years, its underlying causes often remain unknown. We report the case of a 63-year-old man with an atypical clinical presentation of hypersensitive EM and significant coronary artery disease, which was confirmed through coronary angiography. The patient was treated with hydrochlorothiazide $(12.5 \mathrm{mg}$ once daily for 2 years) and budesonide/formoterol (160/4.5 $\mu \mathrm{g}$ once daily for 2 years). Amoxicillin/clavulanic acid (1000/200 mg three times daily for 2 days) and azithromycin (500 $\mathrm{mg}$ once daily for 2 days) were used to treat pneumonia, while ibuprofen (600 mg three times daily for 2 days) was used to treat pericarditis. Extremely high levels of eosinophils led to clinical suspicion of non-acute coronary syndrome as the cause of chest pain and myocardial necrosis. In addition, early pulse doses of methylprednisolone $(500 \mathrm{mg}$ intravenously once daily) were administered. Complete clinical recovery and a fast decrease in eosinophils and troponin levels were observed after a few hours on the same day. No signs of recurrent myocarditis were noticed after 3 days of administering the same pulse doses of methylprednisolone, which was then replaced by oral methylprednisolone administered for the next 2 months (step-down regimen,
\end{abstract}

Dario Gulin

dariogulin@gmail.com

1 Department of Cardiovascular Diseases, University Hospital "Sveti Duh", Sveti Duh 64, 10000 Zagreb, Croatia

2 University of Zagreb, School of Medicine, Zagreb, Croatia

3 General Hospital Sibenik, Sibenik, Croatia

4 Josip Juraj Strossmayer University of Osijek, School of Medicine, Osijek, Croatia starting from $64 \mathrm{mg} / \mathrm{day}$ ). Despite causality assessment being difficult, prompt therapy must be given as soon as possible to prevent fatal outcomes. Delayed corticosteroid treatment, which is necessary regardless of the underlying cause, can result in heart failure and death.

\section{Key Points}

Due to an atypical clinical presentation, hypersensitivity eosinophilic myocarditis is rarely clinically recognised and the cause of the disease frequently remains unknown.

Prompt diagnosis of hypersensitivity eosinophilic myocarditis and appropriate treatment with pulse doses of corticosteroids are crucial, because it can lead to a fatal outcome if left untreated.

\section{Introduction}

Eosinophilic myocarditis (EM) is a rare and potentially fatal disease if left untreated. It is rarely recognised clinically and is often first discovered during a post-mortem examination [1]. There are numerous drugs that have been involved in causing the hypersensitivity form of EM (antibiotics, anticonvulsants and diuretics) but the cause of the disease often remains unknown. The hypersensitivity form may develop early during use of the causative drug or may have a delayed presentation after as long as 2 years. According to Gell and Coombs [2], drug hypersensitivity 
reactions with eosinophilic inflammation and $\mathrm{T}$ helper cell type $2\left(\mathrm{~T}_{\mathrm{h}} 2\right)$ immune response (clinically maculopapular eruptions and a reaction to drugs with eosinophilia and systemic symptoms) present as a type IV reaction, which is a delayed type of hypersensitivity reaction; EM is considered to be a delayed hypersensitivity reaction [2-4].

Signs and symptoms of hypersensitivity (skin rash, fever, eosinophilia and malaise) and non-specific cardiac findings (electrocardiographic changes, tachycardia or elevated cardiac enzymes) suggest hypersensitivity myocarditis [3].

In this case report we present an atypical clinical presentation of hypersensitivity eosinophilic myocarditis, presenting mostly as a respiratory infection with flu-like symptoms with an abnormally high eosinophil count. Coronary angiography revealed significant pathomorphological changes.

\section{Case Report}

A 63-year-old man presented to the emergency department with a history of flu-like symptoms, fever and malaise followed by respiratory-dependent chest pain. The patient had a 2-year history of arterial hypertension and chronic bronchitis, which was treated with hydrochlorothiazide (12.5 mg once daily for 2 years) and budesonide/formoterol (160/4.5 $\mu \mathrm{g}$ once daily for 2 years). There had been no prior animal exposure. Physical examination revealed reduced breathing sounds; there were no signs of heart failure. Laboratory tests revealed leukocytosis (leukocyte count of $16.3 \times 10^{9} / \mathrm{L}$ ) with a slightly elevated eosinophil count of $1.1 \times 10^{9} / \mathrm{L}$ (reference range $0.8 \times 10^{9} / \mathrm{L}$ ), troponin of $1.7 \mu \mathrm{g} / \mathrm{L}$ (reference range $<0.4 \mu \mathrm{g} / \mathrm{L}$ ) and C-reactive protein of $32 \mathrm{mg} / \mathrm{L}$ (reference range $<5.0 \mathrm{mg} / \mathrm{L}$ ). Electrocardiography showed clockwise rotation without changes in the ST/T segment. Echocardiography revealed normal systolic function of the non- dilated left ventricle, a diastolic dysfunction of the first degree, and a slightly diffused and thickened myocardium with minimal pericardial effusion of up to $4 \mathrm{~mm}$ behind the posterior wall of the left ventricle. The possibility of initial right pneumonia was described on the chest radiography, without auscultatory findings confirming the diagnosis. Arterial blood gas analysis determined an adequate respiratory function with normal $\mathrm{pH}$ and gas levels. Despite the uncertainty of the diagnosis of pneumonia, empiric therapy including amoxicillin/clavulanic acid (1000/200 mg three times daily) and azithromycin (500 mg once daily) was administered. Ibuprofen (600 $\mathrm{mg}$ three times daily) was also administered due to the pericardial effusion. After 5 days of hospitalisation, the patient's symptoms did not improve. Moreover, the patient was feeling even sicker, had chills, intensive muscular pain and a cough. His new laboratory tests revealed a leukocyte count of $19.2 \times 10^{9} / \mathrm{L}$ and an eosinophil count of $11.2 \times 10^{9} / \mathrm{L}$ (Fig. 1). Troponin levels rose to $4 \mu \mathrm{g} / \mathrm{L}$. Echocardiography showed no difference as compared with the patient's first check-up. Pulse doses of corticosteroids (methylprednisolone $500 \mathrm{mg}$ intravenously) were administered and all other therapy was discontinued. The patient felt relief $7 \mathrm{~h}$ later. A fall in the absolute leukocyte and eosinophil counts was observed (leukocytes $9 \times 10^{9} / \mathrm{L}$; eosinophils $1.32 \times 10^{9} / \mathrm{L}$ ). No heart rhythm disturbance or heart failure symptoms were noted. Therapy with pulse doses of methylprednisolone (500 mg intravenously for each dose) was continued for up to 3 days, after which it was changed to oral methylprednisolone therapy (initially methylprednisolone $64 \mathrm{mg}$, which was decreased every week for 2 months). Coronary angiography showed two-vessel disease with significant stenosis of the circumflex and right coronary artery. In the same procedure, percutaneous coronary intervention was performed with the implantation of one stent in the circumflex artery (Fig. 2). Endomyocardial biopsy was also performed, which showed no inflammation. Ramipril was initiated as a new antihypertensive therapy and dual
Fig. 1 Leukocyte and absolute eosinophil count chart

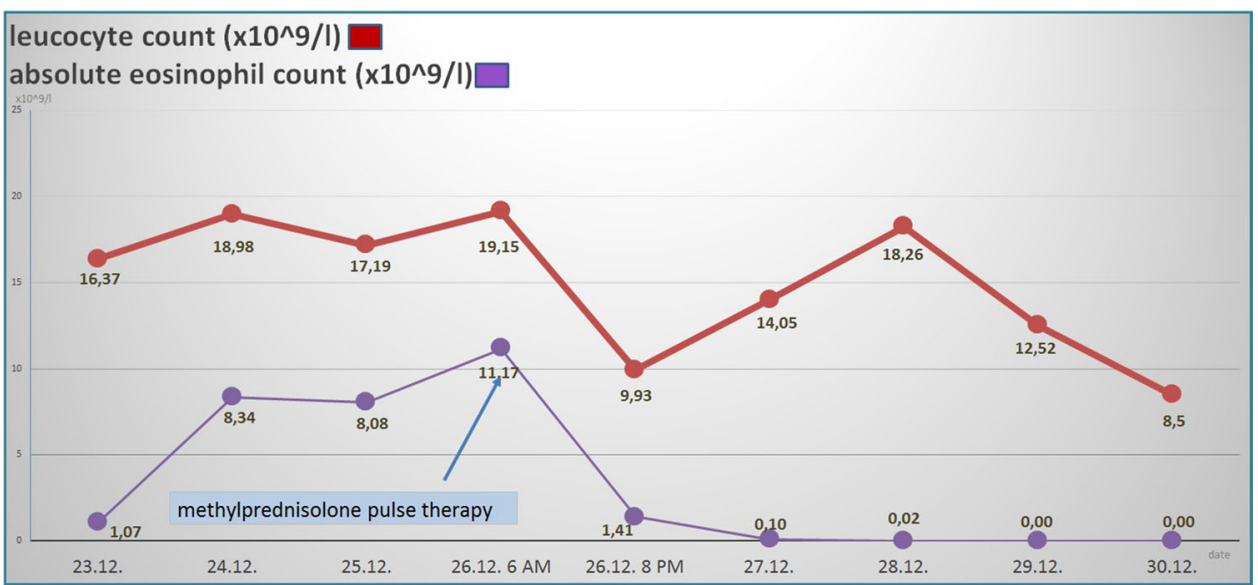


Fig. 2 Significant coronary stenosis of the circumflex artery before percutaneous coronary intervention (a) and successful recanalisation after percutaneous coronary intervention (b)
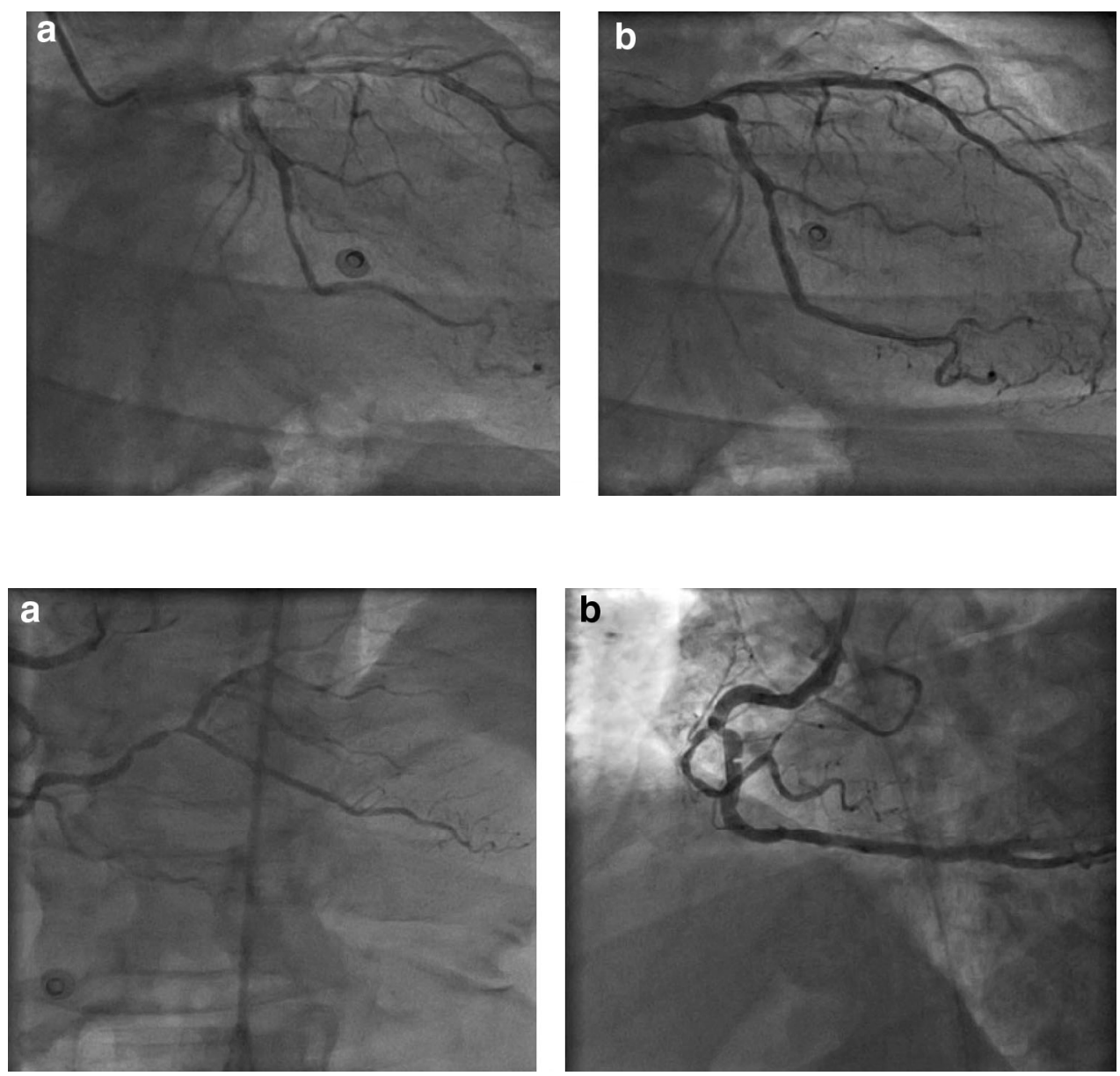

Fig. 3 Significant coronary stenosis of the right coronary artery before percutaneous coronary intervention (a) and successful recanalisation after percutaneous coronary intervention (b) antiplatelet therapy with acetylsalicylic acid and clopidogrel was prolonged.

A second percutaneous coronary intervention was performed 3 weeks later with the implantation of one stent in the right coronary artery (Fig. 3). The clinical status showed no abnormalities. The echocardiography performed showed regular systolic function of both ventricles and that the wall thickness was of the same size as in the first check-up, but without pericardial effusion. The patient was asymptomatic and a complete blood count was normal with normal levels of leukocytes and eosinophils.

\section{Discussion}

EM has high morbidity and mortality rates and early administration of systemic corticosteroids is necessary regardless of the underlying causes because delayed treatment may result in fatal outcomes [4].

The diagnostic criteria proposed by the Japanese Circulation Society Task Force can be very useful in the early recognition of EM. Their criteria include three subgroups: required clinical condition (blood eosinophilia $>0.5 \times 10^{9} /$ $\mathrm{L}$, cardiac symptoms, elevated cardiac enzymes, ECG changes and abnormal echocardiography in the setting of unremarkable coronary angiography); useful information (previous allergy manifestations and flu-like symptoms); and endomyocardial biopsy findings [5]. According to these guidelines, our patient fulfilled enough criteria required for strong suspicion of EM. There were no ECG changes, but as proposed in these guidelines, electrocardiographic changes do not have to be present in $50 \%$ of patients. Respiratory-dependent chest pain with flu-like symptoms and laboratory findings suggested inflammation as a general mechanism of the disease. Echocardiography findings of a thickened wall and pericardial effusion were in favour of myopericarditis. According to the literature, a few case reports of EM have been described with an absolute eosinophil count of $3.5 \times 10^{9} / \mathrm{L}$, but our patient had much higher levels $\left(11.2 \times 10^{9} / \mathrm{L}\right)$ [6]. Endomyocardial biopsy revealed no myocardial inflammation, but it was performed on the third day after a pulse dosage of intravenous corticosteroids when the symptoms had completely disappeared. Also, it should be noted that EM is 
usually a localised inflammatory disease, so bioptic material is not needed to prove the diagnosis as the sample does not have to be taken from inflamed tissue.

There are different types of EM. One of the most common causes described is a hypersensitivity to various drugs, usually antibiotics, anticonvulsants and diuretics. It is possible, but uncommon, that the appearance of druginduced EM can be delayed for up to 2 years $[3,4]$. The fact that drugs that cause one type of idiosyncratic drug reaction with allergic features often cause other types of similar idiosyncratic reactions only causes more doubt regarding the possible aetiology. A high incidence of such idiosyncratic drug reactions is not known to appear with hydrochlorothiazide and there are only a few case reports describing the potential cause of hydrochlorothiazide-induced EM in the literature, which highlights the difficulty of establishing a causal relationship [4, 6]. No connections between budesonide/formoterol and EM were found. In a clinical sense, it is unlikely that antibiotics could have caused EM in this case as the symptoms characterising EM were present before these agents were administrated. Therefore, because the causality assessment is difficult, it is unclear if this myocarditis was drug induced or if it may be idiopathic as well.

It is more obvious that coronary artery disease was a cofinding in this case, because the symptoms of acute coronary syndrome cannot be resolved using corticosteroids, and troponin levels would not decrease on the second day after the therapy was initiated. Trends in leukocyte and absolute eosinophil count support this hypothesis.

\section{Conclusion}

It should be emphasised that proper initial diagnosis of EM and early treatment with pulse doses of intravenous corticosteroid therapy should not be delayed, because untreated myocarditis could result in heart failure and death $[7,8]$.

\section{Compliance with Ethical Standards}

Written informed consent was obtained from the patient for publication of this case report.
Conflict of interest Gulin Dario, Sikic Jozica, Cerkez Habek Jasna, Jerkovic Gulin Sandra and Galic Edvard declare that there are no conflicts of interest concerning the content of this case report.

Funding No financial support was received for the conduct of this case report or preparation of this manuscript.

Open Access This article is distributed under the terms of the Creative Commons Attribution-NonCommercial 4.0 International License (http://creativecommons.org/licenses/by-nc/4.0/), which permits any noncommercial use, distribution, and reproduction in any medium, provided you give appropriate credit to the original author(s) and the source, provide a link to the Creative Commons license, and indicate if changes were made.

\section{References}

1. Winters GL, McManus BM. Myocarditis. In: Silver MD, Gotlieb AI, Schoen FJ, editors. Cardiovascular pathology. Philadelphia: Churchill Livingstone; 2001. p. 256-84.

2. Gell PGH, Coombs RRA. The classification of allergic reactions underlying disease. In: Gell PGH, Coombs RRA, editors. Clinical aspects of immunology. Oxford: Blackwell Science; 1963. p. 217-37.

3. Al Ali AM, Straatman LP, Allard MF, Ignaszewski AP. Eosinophilic myocarditis: case series and review of literature. Can J Cardiol. 2006;22:1233-7.

4. Sohn KH, Song WJ, Kim BK, Kang MK, Lee SY, Suh JW, et al. Eosinophilic myocarditis: case series and literature review. Asia Pac Allergy. 2015;5(2):123-7.

5. Japanese Circulation Society Task Force Committee on Acute and Chronic Myocarditis. Guidelines for diagnosis and treatment of myocarditis (JCS 2009). Circ J. 2011;75:734-743.

6. Burke AP, Saenger J, Mullick F, Virmani R. Hypersensitivity myocarditis. Arch Pathol Lab Med. 1991;115:764-9.

7. Amini R, Nielsen C. Eosinophilic myocarditis mimicking acute coronary syndrome secondary to idiopathic hypereosinophilic syndrome: a case report. J Med Case Rep. 2010;4:40.

8. Aggarwal A, Bergin P, Jessup P, Kaye D. Hypersensitivity myocarditis presenting as cardiogenic shock. J Heart Lung Transplant. 2001;20:1241-4. 